\title{
Variation in the Corticotropin-Releasing Hormone Receptor 1 (CRHR1) Gene Influences fMRI Signal Responses during Emotional Stimulus Processing
}

\author{
David T. Hsu, ${ }^{1,2}$ Brian J. Mickey, ${ }^{1,2}$ Scott A. Langenecker, ${ }^{1,2}$ Mary M. Heitzeg, ${ }^{2}$ Tiffany M. Love, ${ }^{1}$ Heng Wang, ${ }^{1}$ \\ Susan E. Kennedy, ${ }^{3}$ Marta Peciña, ${ }^{1}$ Tal Shafir, ${ }^{1,2}$ Colin A. Hodgkinson, ${ }^{4}$ Mary-Anne Enoch, ${ }^{4}$ David Goldman, ${ }^{4}$ \\ and Jon-Kar Zubieta ${ }^{1,2}$ \\ ${ }^{1}$ Molecular and Behavioral Neuroscience Institute and ${ }^{2}$ Department of Psychiatry, University of Michigan, Ann Arbor, Michigan, 48109, ${ }^{3}$ Department of \\ Biological Sciences, University of Alabama, Tuscaloosa, Alabama, 35487, and ${ }^{4}$ Laboratory of Neurogenetics, National Institute on Alcohol Abuse and \\ Alcoholism, NIH, Bethesda, Maryland 20892
}

The corticotropin-releasing hormone (CRH) system coordinates neuroendocrine and behavioral responses to stress and has been implicated in the development of major depressive disorder (MDD). Recent reports suggest that GG-homozygous individuals of a single nucleotide polymorphism (rs110402) in the CRH receptor 1 (CRHR1) gene show behavioral and neuroendocrine evidence of stress vulnerability. The present study explores whether those observations extend to the neuronal processing of emotional stimuli in humans. CRHR1 was genotyped in 83 controls and a preliminary sample of 16 unmedicated patients with MDD who completed a functional magnetic resonance imaging scan while viewing blocks of positive, negative, and neutral words. In addition, potential mediating factors such as early life stress, sex, personality traits, and negative memory bias were examined. Robust differences in blood oxygenation level-dependent (BOLD) signal were found in healthy controls (A allele carriers > GG-homozygotes) in the right middle temporal/ angular gyrus while subjects were viewing negative versus neutral words. Among GG-homozygotes, BOLD signal in the subgenual cingulate was greater in MDD participants $(n=9)$ compared with controls $(n=33)$. Conversely, among A-carriers, BOLD signal was smaller in $\operatorname{MDD}(n=7)$ compared with controls $(n=50)$ in the hypothalamus, bilateral amygdala, and left nucleus accumbens. Early life stress, personality traits, and levels of negative memory bias were associated with brain activity depending on genotype. Results from healthy controls and a preliminary sample of MDD participants show that CRHR1 single nucleotide polymorphism rs 110402 moderates neural responses to emotional stimuli, suggesting a potential mechanism of vulnerability for the development of MDD.

\section{Introduction}

The corticotropin-releasing hormone $(\mathrm{CRH})$ system plays a critical role in coordinating the autonomic, endocrine, and behavioral responses to stress (Dunn and Berridge, 1990; Owens and Nemeroff, 1991). Dysregulated CRH systems have been associated with major depressive disorder (MDD) (Arborelius et al.,

Received Nov. 2, 2011; revised Jan. 9, 2012; accepted Jan. 19, 2012.

Author contributions: D.T.H., S.A.L., M.M.H., S.E.K., and J.-K.Z. designed research; S.A.L. and S.E.K. performed research; T.M.L., H.W., C.A.H., M.-A.E., and D.G. contributed unpublished reagents/analytic tools; D.T.H., B.J.M., S.A.L., T.M.L., H.W., M.P., T.S., and M.-A.E. analyzed data; D.T.H. wrote the paper.

This work was supported by NIH Grants P01 MH 42251, R01 DA 016423, and R01 DA 022520 (J.-K.Z.), National Alliance for Research on Schizophrenia and Depression (J.-K.Z., S.A.L.), the Phil F. Jenkins Foundation (J.-K.Z.), the Postdoctoral Translational Scholars Program (D.T.H., T.S., UL1RR024986 to the University of Michigan), NIH Grant K01 MH 085035 (D.T.H.), and the Intramural Research Program of the National Institute on Alcohol Abuse and Alcoholism, NIH. We thank the fMRI laboratory (Eve Gochis, Keith Newnham, Dr. Luis Hernandez, and Dr. Douglas Noll), and Virginia Murphy-Weinberg at the University of Michigan for their assistance in the performance of the study.

J.-K.Z. was a consultant for Eli Lilly and Company, Merck, and Johnson and Johnson during the time that the work was conducted and reported; activities were unrelated to the data in the present study. All other authors declare no financial conflicts of interest.

Correspondence should be addressed to Dr. Jon-Kar Zubieta, University of Michigan, Molecular and Behavioral Neuroscience Institute, 205 Zina Pitcher Place, Ann Arbor, MI 48109-0720. E-mail: zubieta@umich.edu.

DOI:10.1523/JNEUROSCI.5533-11.2012

Copyright $\odot 2012$ the authors $\quad 0270-6474 / 12 / 323253-08 \$ 15.00 / 0$
1999). Hypophyseal CRH hypersecretion may cause ACTH and cortisol dysregulation in MDD (Holsboer and Barden, 1996), and central CRH hypersecretion has been demonstrated by elevated basal levels of CRH-like immunoreactivity in the CSF of MDD patients and suicide victims (Nemeroff et al., 1984; Bánki et al., 1987; Widerlöv et al., 1988; Arató et al., 1989). One consequence of CRH hypersecretion may be the downregulation of its major receptor, CRHR1. Postmortem studies have shown that individuals with MDD have decreased CRH binding and levels of CRHR1 mRNA in the frontal cortex, suggesting the role for CRHR1 in the pathophysiology of MDD (Nemeroff et al., 1988; Merali et al., 2004).

Several recent studies have suggested that single nucleotide polymorphisms (SNPs) in the CRHR1 gene are associated with increased incidence of MDD (Liu et al., 2006), and predict antidepressant treatment response (Licinio et al., 2004; Liu et al., 2007). Furthermore, CRHR1 polymorphisms interact with stressful life experiences to predict MDD (Bradley et al., 2008; Wasserman et al., 2008; Heim et al., 2009; Polanczyk et al., 2009; Wasserman et al., 2009; Grabe et al., 2010) and suicide (Wasserman et al., 2008), as well as the initiation and heavy use of alcohol (Blomeyer et al., 2008; Schmid et al., 2010). 
In particular, the common intronic CRHR1 SNP rs1 10402 has been shown to be an important moderator of childhood abuse on hypothalamic-pituitary-adrenal axis functioning and development of MDD (Bradley et al., 2008; Heim et al., 2009; Polanczyk et al., 2009; Tyrka et al., 2009; Ressler et al., 2010). The rs110402 A allele has been shown to have a protective effect against MDD in individuals exposed to childhood abuse (Bradley et al., 2008; Polanczyk et al., 2009). However, beyond neuroendocrine effects, it is not known whether CRHR1 rs110402 affects brain regions involved in emotion processing and the pathophysiology of MDD.

The present study uses functional magnetic imaging (fMRI) in healthy controls and a preliminary sample of MDD patients to examine how rs110402 genotypes influence brain responses to emotional stimuli. Four a priori brain regions previously shown to exhibit abnormal activity in MDD were examined: the subgenual cingulate cortex, hypothalamus, amygdala, and nucleus accumbens (Drevets, 1999; Whalen et al., 2002; Bao et al., 2008; Pizzagalli et al., 2009). As suggested by the studies above, early life stress as well as sex (Heim et al., 2009) were examined as potential factors mediating the effects of rs110402 on brain activity. Furthermore, vulnerable personality traits were hypothesized to be associated with the effects of rs 110402, including the Neuroticism dimension of the Revised NEO Personality Inventory (Costa and McCrae, 1992), and the Behavioral Inhibition System scale, which measures aversive motivation relating to feelings of fear, anxiety, frustration, and sadness (Gray, 1990; Carver and White, 1994).

\section{Materials and Methods}

Subjects. Genotyping was performed in 128 healthy controls (70 males, mean age $\pm S D, 26 \pm 6$ years; 58 females, $28 \pm 8$ years), and 22 unmedicated patients with current MDD ( 8 males, $41 \pm 12$ years; 14 females, $39 \pm 11$ years). Controls were screened for active medical illness and for current or past psychiatric disorders in themselves or first-degree relatives. MDD volunteers were diagnosed with the Structured Clinical Interview for DSM-Clinical Version (SCID-IV), scored $>15$ (mean score \pm SD, $19 \pm 3$ ) on the 17-item Hamilton Depression Rating Scale, and were free of antidepressant medication for at least 6 months at the time of the study (mean duration of illness \pm SD, $21 \pm 32$ months; range, $1.5-132$ months). None of the volunteers were taking psychotropic medications, including hormones or hormonal contraception in women.

Ninety-nine controls and $22 \mathrm{MDD}$ were asked to complete an fMRI emotion word stimulus task. Pregnancy tests and urine drug screens were confirmed negative before scanning. Two patients with MDD did not complete the task, and 16 controls and four MDD patients were excluded for artifacts in fMRI data or excessive head movement $(>2 \mathrm{~mm}$ of translation or 2 degrees of rotation) that resulted in less than two valid scan sessions. In total, usable fMRI data were obtained from 83 controls (45 males, mean age \pm SD, $27 \pm 7$ years; 38 females, $29 \pm 8$ years) and 16 patients with MDD ( 5 males, $43 \pm 13$ years; 11 females, $39 \pm 12$ years).

Written informed consent was obtained and study protocols were approved by the Institutional Review Board of the University of Michigan Medical School.

Genotyping. DNA was extracted from whole blood. A genomic region of chromosome 17 containing sequence $5 \mathrm{~kb}$ upstream and $1 \mathrm{~kb}$ downstream of CRHR1 was retrieved from NCBI Human Build 35.1. CRHR1 rs110402, located in intron 2, was genotyped using the Illumina GoldenGate platform (Hodgkinson et al., 2008). The genotyping in controls $(\mathrm{AA}=27, \mathrm{AG}=54, \mathrm{GG}=47)$ was in Hardy Weinberg Equilibrium $(p=$ $0.15)$. The minor (A) allele frequency was 0.42 . Genotypes in the MDD sample were as follows: $\mathrm{AA}=6, \mathrm{AG}=4, \mathrm{GG}=12$.

To determine whether population stratification might have an influence on the outcome, samples were genotyped for 186 ancestry informative markers (AIMs) (Hodgkinson et al., 2008). The same AIMs were genotyped in 1051 individuals from the 51 worldwide populations represented in the HGDP-CEPH Human Genome Diversity Cell Line Panel (http://www.cephb.fr/HGDP-CEPH-Panel). Structure 2.2 (http://pritch.bsd.uchicago.edu/software.html) was run simultaneously using the AIMs genotypes from our sample and the 51 $\mathrm{CEPH}$ populations to identify population substructure and compute individual ethnic factor scores. This ancestry assessment identifies seven ethnic factors (Hodgkinson et al., 2008). Mann-Whitney $U$ tests were conducted to compare ethnic factors between A-allele carriers versus GG-homozygous groups, and Spearman's rank correlation coefficients were calculated for ethnic factors versus fMRI BOLD signal.

Emotion word stimulus task. During fMRI, blocks of positive, negative, and neutral words were presented with an LCD video display in the bore of the MR scanner. Subjects were instructed to read the word silently and press a button on a fiber-optic keypad device with their right index finger to indicate that they understood the word. Words were selected from the Affective Norms for English Words (ANEW) list, which provides a normative emotional rating for a large number of words in the English language (Bradley and Lang, 1999). The words in the ANEW list were rated on the dimensions of valence and arousal on a scale of 1 (negative valence; low arousal) to 9 (positive valence; high arousal). For the present study, we chose negative words from this list that had an average valence rating of $<3$, neutral words with valence ratings between 4.5 and 5.5 and positive words with a valence rating $>7$. Standard deviations for all valence ratings were $<2$ and arousal ratings were $>3$. Word length ranged from 3 to 11 letters (mean number of letters \pm SD, $6.04 \pm 1.64$ ).

Words were presented one at a time $(3 \mathrm{~s}$, followed by $1 \mathrm{~s}$ cross-hair orientation) in blocks of six words of the same valence. Six blocks (with two blocks from each condition: positive, negative, neutral) constituted one run. Nonactive rest blocks of $18 \mathrm{~s}$ were interspersed between each block. Block order was counterbalanced using a Latin squares design in each of three runs. Subjects with usable data from at least two runs were included in the analyses.

Following the scan, a subset of control $(n=18)$ and $\operatorname{MDD}(n=18)$ subjects were administered a memory recall and recognition test without prior warning to evaluate implicit recall and recognition memory, using percentage word recall and recognition, respectively. Negative memory bias is characteristic of MDD (Leppänen, 2006) and was determined by subtracting percentage recall or recognition of neutral words from percentage recall or recognition of negative words. These values were used for group comparisons and regression with fMRI activity.

The emotional words task was chosen over other emotional probes (e.g., faces, pictures) to test the hypothesis that cognitive distortions are affected by vulnerable genotypes. Emotional words may require more cognitive processing effort (i.e., memory, associations), which may be more subtly influenced by functional differences in CRHR1. For example, recent evidence suggests that CRHR1 modulates early-life stressmediated cognitive deficits in animals (Ivy et al., 2010; Wang et al., 2011).

$f M R I$ data acquisition. Whole-brain scans were performed using a 3.0 tesla Signa scanner (GE Healthcare) using a standard radio frequency coil. Blood oxygenation level-dependent (BOLD) signal was acquired using a T2*-weighted pulse sequence (repetition time, $2000 \mathrm{~ms}$; echo time, $30 \mathrm{~ms}$; flip angle, $90^{\circ}$; field of view, $24 \mathrm{~cm}, 64 \times 64$ matrix; 1 voxel, $3.75 \times 3.75 \times 4 \mathrm{~mm}$ ) with single-shot combined spiral in/out acquisition (Glover and Law, 2001), which has been shown to reduce signal dropout in areas prone to high susceptibility artifacts. The entire volume of brain (30 slices) was acquired at each repetition time. A high resolution T1weighted pulse sequence was acquired to provide anatomical localization (three-dimensional spoiled gradient recalled echo; repetition time, 24 $\mathrm{ms}$; echo time, $5 \mathrm{~ms}$; flip angle, $45^{\circ}$; field of view, $24 \mathrm{~cm}, 256 \times 256$ matrix; slice thickness, $1.5 \mathrm{~mm}$ ).

fMRI data analysis. BOLD contrasts were slice-time corrected, realigned, smoothed with an $8 \times 8 \times 8$ Gaussian filter, and analyzed with Statistical Parametric Mapping v.2 (SPM2; Wellcome Institute of Cognitive Neurology, London, UK). Contrast $t$ maps for each subject were derived using a primary subtraction of negative or positive word blocks minus neutral word blocks (Neg - Neut or Pos - Neut) with head movement regressors, normalized with linear and nonlinear warping to standard (Montreal Neurological Institute) space and smoothed with a 6 $\mathrm{mm}$ Gaussian filter to reduce residual interindividual anatomical vari- 
ability. Interindividual, random-effects analyses were performed using SPM2.

Control subjects with the potentially protective CRHR1 rs110402 A allele were grouped (i.e., AA and AG) to increase power. Whole-brain analysis was conducted for comparing A-carriers versus GG-homozygous individuals in the Neg - Neut and Pos - Neut contrasts. Threshold was set at $p<0.05$, correcting for false discovery rate (FDR) for whole brain, two-tailed. Peak activation ( $p<0.025$, FDR-corrected) was extracted for further analyses using MarsBaR VOI toolbox (version 0.38) (Brett et al., 2002) for SPM and analyzed with SPSS statistical software (version 16.0) to plot the data and rule out the presence of outliers using the Tukey box plot, where an outlier is defined as a score $>1.5$ interquartile lengths from the first or third quartile.

For comparing MDD patients with controls, volumes of interest (VOI) analyses were chosen over whole-brain analyses because of the small sample size of MDD patients. Four a priori brain regions previously shown to exhibit abnormal activity in MDD were examined: the subgenual cingulate cortex (Drevets et al., 1999; Mayberg et al., 1999, 2000; Langenecker et al., 2007; Keedwell et al., 2010), hypothalamus (Bao et al., 2008), bilateral amygdala (Whalen et al., 2002), and bilateral nucleus accumbens (Pizzagalli et al., 2009). These regions are also closely interconnected (Hsu and Price, 2007, 2009) and have high levels of CRHR1 (Millan et al., 1986; Sánchez et al., 1999). Activation in these VOIs was considered statistically significant at $p<0.05$, FDR-corrected within VOI, two-tailed. Using anatomical boundaries, VOIs were manually created for the subgenual cingulate cortex (rectangular box), hypothalamus (rectangular box), and nucleus accumbens (sphere); MarsBaR automated anatomical labeling (Tzourio-Mazoyer et al., 2002) was used for

the amygdala (Table 1). Alpha levels were Bonferroni-adjusted for four comparisons $(p=0.0125)$.

Questionnaires. Vulnerable personality traits examined included the neuroticism dimension of the Revised NEO Personality Inventory (PI) (Costa and McCrae, 1992) and the Behavioral Inhibition System (BIS) scale, which measures aversive motivation relating to feelings of fear, anxiety, frustration, and sadness (Gray, 1990; Carver and White, 1994). Correlations were considered statistically significant at $p<0.05$, twotailed. Correlations with the six facets of neuroticism (anxiety, hostility, depression, self-consciousness, impulsiveness, vulnerability to stress) were considered statistically significant after Bonferroni-adjusting for six comparisons.

Early life stress was scored with the Childhood Trauma Questionnaire (CTQ) (Bernstein et al., 1994) and specific items from the Family Experiences Questionnaire (FEQ) (Durrett et al., 2004). The CTQ is a 25-item inventory that provides a brief, reliable, and valid measure of childhood abuse and neglect. The FEQ is a more comprehensive evaluation of childhood experiences with 133 items. Ten items from the FEQ that overlapped with the CTQ were chosen, including sexual contact, physical abuse, physical neglect, and emotional neglect, each weighted by the length/severity of these episodes. Most control subjects completed the FEQ $(n=72)$ and some completed the CTQ $(n=11)$. Standard $(z)$ scores were computed for total raw scores from the CTQ and FEQ and used for group comparisons and regression with fMRI activity in controls. Thirteen patients with MDD completed the CTQ only.

\section{Results}

Whole-brain analysis of Neg - Neut blocks in healthy controls showed greater regional activation in A-carriers $(n=50)$ compared with GG-homozygotes $(n=33)$.
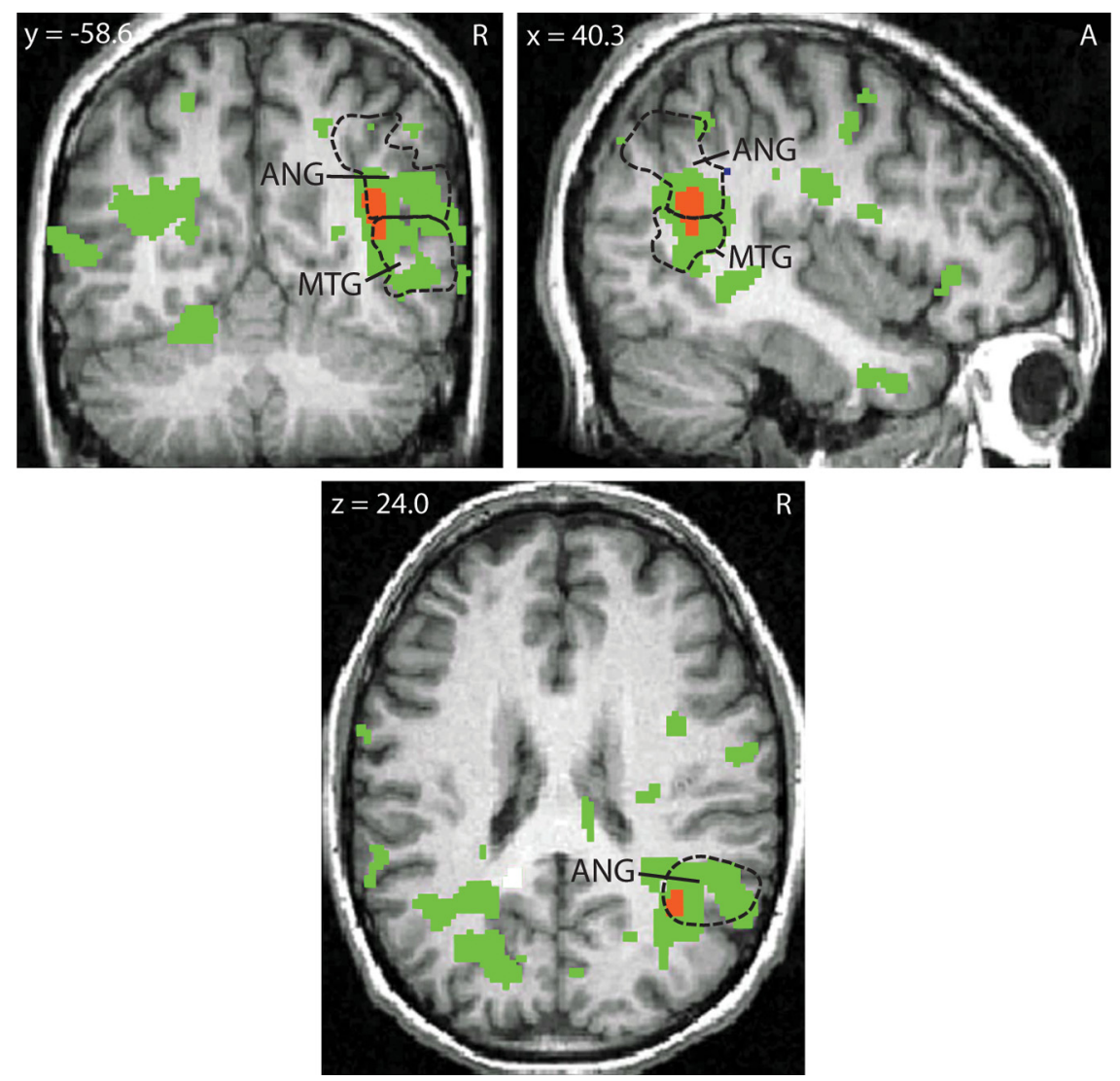

Figure 1. fMRI BOLD activity (Neg - Neut) in controls: A-carriers $>$ GG-homozygotes. Peak activation differences in a whole-brain analysis found in the right middle temporal/angular gyrus. Green areas indicate $p<0.05$, FDR-corrected for whole brain, two-tailed. Red area indicates $p<0.025$, FDR-corrected for whole brain, two-tailed, cluster size $=560 \mathrm{~mm}^{3}$; Montreal Neurological Institute stereotactic space coordinates of peak activation: $x=38, y=-60, z=26$. Dashed lines indicate the anatomical boundaries of the right middle temporal and angular gyrus. ANG, Angular gyrus; MTG, middle temporal gyrus; , $_{\text {, }}$ anterior; $\mathrm{R}$, right.
Robust differences were found in a cluster that spanned the right middle temporal gyrus [posterior part; Brodmann area (BA) 21] and angular gyrus (BA 39) $(p=$ 0.011 , FDR-corrected for whole brain, two-tailed; Fig. 1). Extraction of peak differences in the angular gyrus showed greater activation to negative words in A-carriers, and greater activation to neutral words in GG-homozygotes $\left(t_{81}=\right.$ 5.61, $p<0.025$, FDR-corrected for whole brain, two-tailed). Mean BOLD percentage change values extracted from peak activation for Neg - Neut $( \pm$ SEM) were as follows: A-carriers, 0.070 (0.017); GGhomozygotes, $-0.110(0.027)$. No suprathreshold clusters were found for GG > A-carriers in healthy controls. No significant effects were found in Pos Neut comparisons, indicating the gene effect is specific to negative words and not simply to words with high arousal. Sex and age entered as covariates did not affect these results. There were no differences between MDD patients and healthy controls, stratified by genotype, in a whole-brain analysis.

Positive relationships between behavioral traits and BOLD responses were found in GG-homozygotes, but not A-carriers. Activation in the Neg - Neut BOLD contrast in the middle temporal/ angular gyrus was significantly correlated with neuroticism $(r=0.42, p=0.034)$ and the neuroticism facet vulnerability to 
Table 1. V0I analysis (Neg - Neut) in MDD patients versus controls

\begin{tabular}{|c|c|c|c|c|}
\hline V0l & V0I center of mass & V0l volume $\left(\mathrm{mm}^{3}\right)$ & Peak activation & $t$ \\
\hline \multicolumn{5}{|l|}{ GG-homozygotes } \\
\hline \multicolumn{5}{|l|}{ MDD patients (GG) > controls (GG) } \\
\hline Subgenual cingulate (BA 25/32) & $0,24,-7$ & 2520 & $-2,28,-6$ & $4.60^{*}$ \\
\hline \multicolumn{5}{|l|}{ MDD patients (GG) > controls (all) } \\
\hline Subgenual cingulate (BA 25/32) & $0,24,-7$ & 2520 & $-2,28,-6$ & $4.10^{*}$ \\
\hline \multicolumn{5}{|l|}{ A-allele carriers } \\
\hline \multicolumn{5}{|l|}{ Controls $(A-)>$ MDD patients $(A-)$} \\
\hline Hypothalamus & $0,-5,-11$ & 1080 & $4,-6,-12$ & $3.96^{*}$ \\
\hline Amygdala (L) & $-24,-2,-19$ & 1760 & $-30,0,-18$ & 3.81 \\
\hline Amygdala (R) & $27,-1,-19$ & 1984 & $26,0,-20$ & 3.67 \\
\hline Nucleus accumbens $(\mathrm{L})$ & $-8,8,-10$ & 264 & $-8,8,-10$ & $3.56^{*}$ \\
\hline Nucleus accumbens (R) & $8,8,-10$ & 264 & $10,8,-8$ & 2.05 \\
\hline \multicolumn{5}{|l|}{ Controls (all) $>$ MDD patients $(A-)$} \\
\hline Hypothalamus & $0,-5,-11$ & 1080 & $6,-6,-10$ & 3.46 \\
\hline Amygdala (L) & $-24,-2,-19$ & 1760 & $-30,2,-18$ & $3.45^{*}$ \\
\hline Amygdala (R) & $27,-1,-19$ & 1984 & $26,0,-20$ & $3.98^{*}$ \\
\hline Nucleus accumbens (L) & $-8,8,-10$ & 264 & $-6,10,-12$ & 2.76 \\
\hline Nucleus accumbens (R) & $8,8,-10$ & 264 & $6,10,-8$ & 1.45 \\
\hline
\end{tabular}

VOI center of mass and Peak activation in $x, y, z$ coordinates from Montreal Neurological Institute stereotactic space. Alpha levels were Bonferroni-adjusted to 0.0125 for examining four brain regions. ${ }^{*} p<0.01$, FDR-corrected within V0l, two-tailed. R, Right; L, left.

stress $(r=0.51, p=0.008)$, as well as with behavioral inhibition $(r=0.45, p=$ 0.022 ). Controlling for sex in a partial correlation showed that sex explained the relationship between BOLD responses and neuroticism $(r=0.263, p=0.204)$, vulnerability to stress $(r=0.417, p=0.038)$, and behavioral inhibition $(r=0.284, p=$ $0.170)$. Controlling for age did not affect the zero-order correlation. Further analyses revealed that female GG-homozygotes had significantly higher scores than male GG-homozygotes for neuroticism $\left(t_{24}=\right.$ 2.42, $p=0.023)$ and behavioral inhibition $\left(t_{24}=2.74, p=0.011\right)$, but not for vulnerability to stress $\left(t_{24}=1.78, p=0.088\right)$. Female A-carriers were not significantly different from male A-carriers on these three traits.

Differences between MDD patients and healthy controls, stratified by genotype, were also tested in the four a priori brain regions, with alpha levels Bonferroni-adjusted for four comparisons. Among GG-homozygotes, BOLD signal in the subgenual cingulate was greater in MDD patients $(n=9)$ compared with controls $(n=33)$ in response to Neg - Neut words $\left(t_{40}=4.60\right.$, $p=0.0014$, FDR-corrected within VOI, two-tailed; Table 1). Display of whole-brain activation shows specificity in the subgenual cingulate (Fig. 2). Mean BOLD percentage change values extracted from peak activation for Neg - Neut $( \pm$ SEM) were as follows: controls, -0.063 (0.027); MDD, 0.181 (0.052). Conversely, among A-carriers, BOLD signal was smaller in MDD patients $(n=7)$ compared with controls $(n=50)$ in the hypothalamus $\left(t_{55}=3.96, p=0.0037\right.$, FDR-corrected within VOI, two-tailed $)$ and left nucleus accumbens $\left(t_{55}=3.56, p=0.0058\right.$, FDR-corrected within VOI, two-tailed; Table 1). Bilateral amygdala activations approached Bonferroni-adjusted alpha levels (left: $t_{55}=3.81, p=0.015$; right: $t_{55}=3.67, p=0.015$, FDR-corrected within VOI, two-tailed; Table 1). Display of whole-brain activation shows specificity in these areas (Fig. 3). Mean BOLD percentage change values extracted from peak acti-

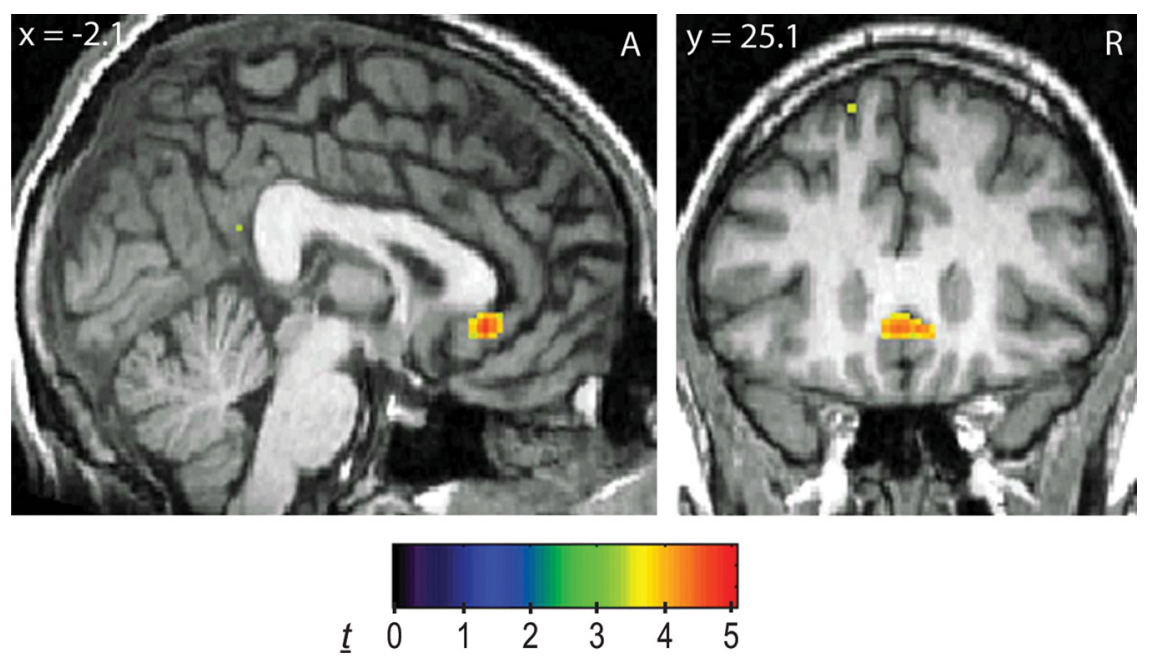

Figure 2. fMRI BOLD activity (Neg - Neut) for GG-homozygotes: MDD patients > controls. Display of whole-brain activation showing specific difference in the subgenual cingulate. Display threshold: $p<0.001$. A, Anterior; R, right.

vation for Neg - Neut ( \pm SEM) were as follows: hypothalamus (Fig. 3A): controls, 0.070 (0.024); MDD, -0.197 (0.083); left amygdala (Fig. 3B): controls, 0.011 (0.026); MDD, -0.279 (0.068); right amygdala (Fig. $3 B$ ): controls: -0.008 (0.039); MDD, -0.464 (0.158); left nucleus accumbens (Fig. $3 C$ ): controls, 0.048 (0.020); MDD, -0.146 (0.052). Similar results were obtained when A-carrier MDD subjects or GG-homozygote MDD patients were compared with all controls, regardless of genotype, including significant activation in the subgenual cingulate and bilateral amygdala (Table 1). No suprathreshold clusters were found for controls (GG-homozygotes or all controls) > MDD or MDD > controls (A-carriers or all controls). Sex and age entered as covariates did not affect these results.

Control analyses indicated that genetic/ethnic stratification did not account for these findings. In our study sample the mean (SD) [median] ethnic factor scores were as follows: European, $0.66(0.39)$ [0.90]; African, 0.14 (0.30) [0.00]; Asian, 0.08 (0.18) [0.01]; MidEastern, 0.07 (0.17) [0.02]; Far Eastern, 0.02 (0.11) [0.00]; Oceania, 0.01 (0.02) [0.00]; America, 0.01 (0.04) [0.00]. The seven ethnic 

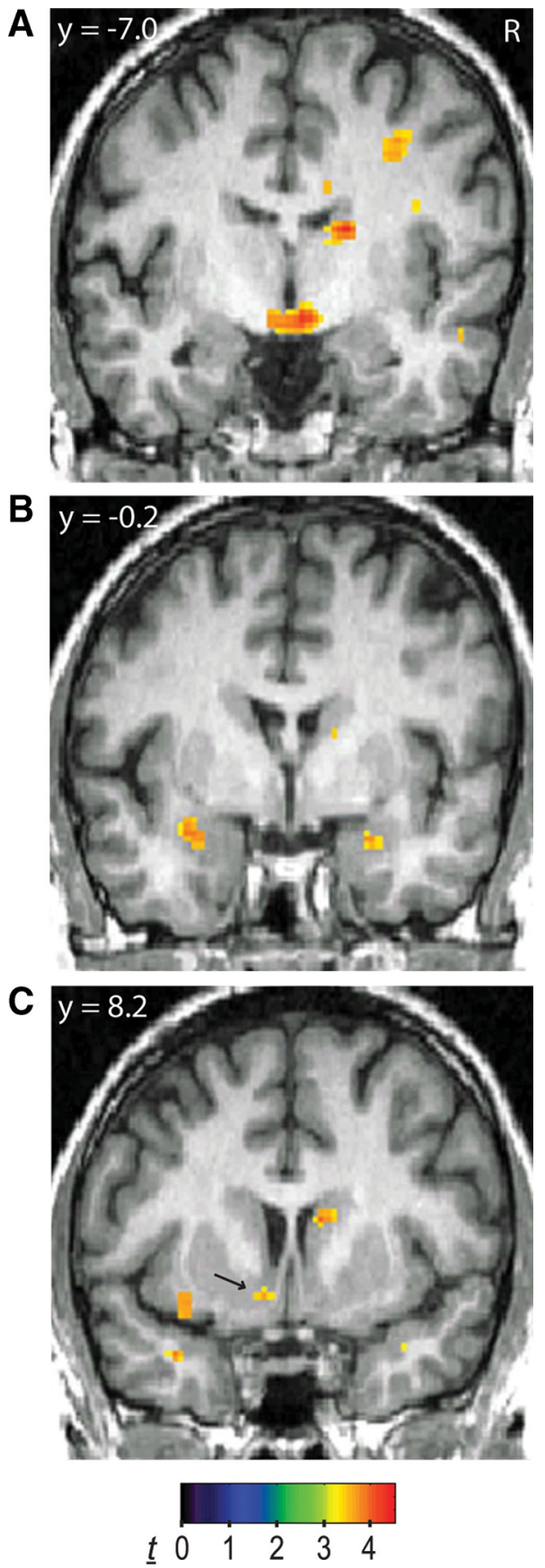

Figure 3. fMRI BOLD activity (Neg - Neut) for A-carriers: controls $>$ MDD patients. $A-C$, Display of whole-brain activation showing specific differences in the hypothalamus $(\boldsymbol{A})$, bilateral amygdala $(\boldsymbol{B})$, and left nucleus accumbens ( $\boldsymbol{C}$, arrow). Display threshold: $p<0.001$. $\mathrm{R}$, Right.

factors did not differ significantly between A-carriers and GGhomozygotes in controls or MDD patients (alpha level Bonferroniadjusted to $0.05 / 7=0.007 ; z,-2.30-2.12 ; p, 0.02-0.67$ ). Spearman's rank correlation did not reveal significant relationships between ethnic factors and Neg - Neut BOLD percentage change in the angular gyrus in controls (alpha level Bonferroni-adjusted to $\left.0.007 ; r_{\mathrm{s}},-0.20-0.07 ; p, 0.07-0.93\right)$. In addition, Spearman's rank correlation did not reveal significant relationships between ethnic factors and Neg - Neut BOLD percentage change in the extracted VOIs (alpha level Bonferroni-adjusted to $0.05 /[7 \times 5]=$ 0.001 ) in controls or MDD patients (subgenual cingulate cortex: $r_{\mathrm{s}}$,
-0.17-0.22; $p, 0.03-0.82$; hypothalamus, $r_{\mathrm{s}},-0.12-0.21 ; p, 0.04-$ 0.93 ; left amygdala: $r_{\mathrm{s}},-0.12-0.23 ; p, 0.02-0.85$; right amygdala: $r_{\mathrm{s}}$, $-0.19-0.14 ; p, 0.06-0.89$; left accumbens: $r_{s},-0.19-0.10 ; p$, 0.07-0.87).

In controls, early life stress scores were not associated with Neg - Neut BOLD activity in the middle temporal/angular gyrus in A-carriers or GG-homozygotes. In VOIs, early life stress scores were negatively correlated with Neg - Neut BOLD activity in the hypothalamus $(r=-0.30, p=0.046)$ only in the A-carriers $(n=$ $45)$. Conversely, early life stress scores were negatively correlated with Neg - Neut BOLD activity in the left amygdala $(r=-0.36$, $p=0.056)$ only in the GG-homozygotes $(n=29)$, although this relationship was not statistically significant. Early life stress scores did not differ between A-carriers and GG-homozygotes. In the preliminary sample of MDD patients, total CTQ scores, or specific items such as physical abuse, were not correlated with activity in the brain regions examined.

Negative recognition (but not recall) memory bias was greater in MDD patients compared with controls $\left(t_{34}=2.66, p=0.01\right.$, two-tailed). In controls, negative recognition memory bias was negatively correlated with Neg - Neut BOLD activity in the hypothalamus in GG-homozygotes $(r=-0.76, p=0.046)$, and positively correlated in A-carriers, although this did not reach significance $(r=0.58, p=0.080)$. In MDD patients, negative recall memory bias was also positively correlated with Neg Neut BOLD activity in the subgenual cingulate, but only in GGhomozygotes $(r=0.81, p=0.008)$.

\section{Discussion}

To our knowledge, this is the first study to examine the effect of CRHR1 SNP rs110402 on neuronal emotional processing. This SNP, which has been associated with dysregulated neuroendocrine stress responses and MDD, showed robust activity differences in the right middle temporal/angular gyrus between A-carriers and GG-homozygotes in response to emotional lexical stimuli in healthy controls. In a preliminary sample of MDD patients, GG-homozygotes showed greater BOLD response compared with controls in the subgenual cingulate, a region implicated in the pathophysiology of MDD (Drevets et al., 1999; Mayberg et al., 1999, 2000; Langenecker et al., 2007; Keedwell et al., 2010). Conversely, A-carriers with MDD showed lesser BOLD responses compared with controls in the hypothalamus, amygdala, and nucleus accumbens. These findings identify brain regions and activity patterns that may mediate the association between this SNP and vulnerability to MDD.

BOLD response to Neg - Neut words was significantly greater in A-carriers compared with GG-homozygotes in the right middle temporal/angular gyrus (BA 21/39). This difference was driven in part by lesser Neg - Neut activity in GG-homozygotes. Lesser activity in the middle temporal gyrus (BA 21) in response to Neg - Neut words has also been found in a sample of healthy subjects (Kuchinke et al., 2005), although genotype was not examined. It is possible that this lesser activity was driven by GGhomozygotes, since our results suggest that there is overall lesser activity in this region when the two groups are combined. Similarly, cerebral blood flow decreased in the angular gyrus when bank officials were shown videos of an armed robbery that they had recently witnessed (Fredrikson et al., 1997). In a study with MDD patients, Canli et al. (2004) found reduced BOLD activity in response to negative words in the superior temporal gyrus (BA 22 ) in MDD patients compared with healthy controls. These data, along with the present study, suggest common areas in the temporal cortex specific to semantic retrieval (Price, 2000) and atten- 
tional processing of emotional stimuli (Davidson et al., 1999) that exhibit lesser activity in response to negative emotional stimuli. Here we show that this decrease was more pronounced in GG-homozygotes of rs110402.

Greater activity in A-carriers compared with GG-homozygotes in the right middle temporal/angular gyrus might also suggest that A-carriers were more successful at cognitive reappraisal of negative emotions. Using distancing as a method for cognitive reappraisal of negative social scenes, Koenigsberg et al. (2010) found that distancing compared with looking (Neg Neut) resulted in increased activity in the right middle temporal gyrus, similar to the present comparison of A (Neg - Neut) GG (Neg - Neut). Similarly, cognitive reappraisal of negative pictures specifically involved the middle temporal and angular gyrus (BA 21/39) (McRae et al., 2010). It is therefore possible that A-carriers in our study were more successful at automatic cognitive reframing; however, the volunteers in our study were not asked to use reappraisal strategies. Consistent with this hypothesis, GG-homozygotes and A-carriers showed differential associations between negative recognition memory bias and Neg - Neut hypothalamic activity. GG-homozygotes showed a negative correlation between negative recognition memory bias, whereas A-carriers showed a positive correlation, although the latter was not statistically significant. This suggests that hypothalamic Neg - Neut activity in A-carriers and GG-homozygotes is differentially mediated by negative memory bias, potentially through different cognitive reappraisal strategies.

Among GG-homozygotes, women showed increased levels of neuroticism and behavioral inhibition compared with men. These sex differences were not found in A-carriers. High neuroticism, as measured by the NEO-PI, is associated with increased risk of MDD (Boyce et al., 1991; Kendler et al., 1993). The BIS and Behavioral Activation System (BAS) are based on a theory of limbic-cortical systems involved in behavioral activation and inhibition in response to punishment or reward (Gray, 1990), and lower BAS/higher BIS levels are found in MDD patients compared with controls (Kasch et al., 2002). Thus, vulnerability to MDD may be increased in female GG-homozygotes. The vulnerability of GG-homozygotes to MDD may in turn depend on exposure to moderate to severe childhood trauma (Bradley et al., 2008; Heim et al., 2009; Polanczyk et al., 2009; Tyrka et al., 2009; Ressler et al., 2010). A significant negative correlation was found between early life stress and hypothalamus activation only in A-carriers, and a near-significant negative correlation was found between early life stress and left amygdala activation only in GG-homozygotes, suggesting that early life stress differentially impacts emotional processing in A-carriers and GG-homozygotes. Larger studies are needed to determine the impact of early life stress on brain activity in A-carriers and GG-homozygotes. For example, one study found a three-way interaction of early abuse, sex, and rs110402 on adult depressive symptoms, whereby the specific types of abuse mediated the effect of sex (Heim et al., 2009).

In our preliminary sample of MDD participants, GGhomozygotes showed greater BOLD activity in the subgenual cingulate compared with controls while viewing Neg - Neut words. This activation was not found in A-carriers, raising the possibility that in MDD, subgenual BOLD activation to negative emotional stimuli is specific to GG-homozygotes of CRHR1 rs110402. Increased subgenual activation may reflect greater self-referential processing and attempts at emotional regulation in GG-homozygotes, consistent with the hypothesized role of the subgenual cingulate (Berman et al., 2011). Similar to our results, increased subgenual BOLD activity in MDD participants has been observed while viewing sad faces (Gotlib et al., 2005) and during rumination (Cooney et al., 2010) compared with controls. Since the GG genotype has been associated with MDD (Bradley et al., 2008; Polanczyk et al., 2009; Heim et al., 2009; Tyrka et al., 2009; Ressler et al., 2010; present study), it would be of interest to determine whether that effect is more pronounced or even driven by GG-homozygotes, and not A-carriers, with MDD. The possibility that GG-homozygotes of CRHR1 rs110402 represent a genetically driven subtype of MDD may have clinical implications, as hyperactive subgenual activity has been associated with better treatment response in medication trials (Mayberg et al., 2000). Interestingly, the frequency of GGhomozygotes was greater in MDD patients compared with that of controls (MDD: A- = 10, GG = 12; controls: A- = 81, GG = 47), although a larger sample is needed to conclude that the GGhomozygotes are overrepresented in MDD patients.

A-carriers with MDD showed lesser BOLD activity in the hypothalamus, amygdala, and nucleus accumbens compared with controls while viewing Neg - Neut words. This effect was not found in GG-homozygotes. The A allele of rs110402 has been shown to have a protective effect against MDD in the presence of childhood abuse (Bradley et al., 2008; Heim et al., 2009; Polanczyk et al., 2009). Deactivation in the amygdala and nucleus accumbens may reflect a lack of motivational value for negative stimuli, as both regions are involved in the representation and encoding of stimulus saliency (Zink et al., 2004; Adolphs, 2008). These regions are further interconnected with each other and the hypothalamus (Heimer et al., 1991; Amaral et al., 1992), potentially regulating neuroendocrine function and resulting in a protective effect. Increased and sustained amygdala activity in response to emotional stimuli has been reported in MDD (Sheline et al., 2001; Siegle et al., 2002), however, the decreased amygdala activity in MDD A-carriers found in the present study may reflect a subgroup responding differently to emotional stimuli. The finding that negative recall memory bias was positively correlated to subgenual cingulate activity only in MDD GGhomozygotes suggests differences in the processing of emotional stimuli in A-carriers and GG-homozygotes. How some individuals develop MDD despite having the protective A allele is not known and requires further study.

The mechanism by which rs110402 affects the function of CRHR1 is presently unknown. Variations of rs110402 may affect the regulation of CRHR1 receptors, resulting in the pattern of BOLD activity observed in GG-homozygotes with MDD in the subgenual cingulate. Although CRHR1 regulation has not been specifically studied in the subgenual cingulate, in other prefrontal areas (BA 9, 10, 11), CRH binding sites and CRHR1 mRNA were downregulated in MDD suicides (Nemeroff et al., 1988; Merali et al., 2004). Limitations of the present study include a relatively small sample of MDD patients, the results from which should be considered preliminary. The observed differences between MDD and controls were relatively large and specific to brain regions with known abnormalities in MDD; however, the small and unbalanced groups limit the generalizability of the results to the MDD population and warrants further investigation and replication in a larger sample before conclusions can be definitively drawn.

In conclusion, the present study demonstrates that CRHR1 rs110402 influences brain responses to negative emotional stimuli. These include greater Neg - Neut activity in the middle temporal/angular gyrus in A-carriers compared with GGhomozygotes in healthy individuals. In a preliminary sample of MDD patients, GG-homozygotes exhibited greater activity in the subgenual cingulate cortex compared with healthy controls, and 
A-carriers exhibited lesser responses in limbic areas compared with healthy controls. The results also show evidence for influencing factors such as early life stress, personality traits, and levels of negative memory bias, that are associated with brain activity to negative emotional stimuli depending on CRHR1 rs110402. These findings help explain how differences in the CRHR1 gene may contribute to vulnerability to MDD.

\section{References}

Adolphs R (2008) Fear, faces, and the human amygdala. Curr Opin Neurobiol 18:166-172.

Amaral DG, Price JL, Pitkänen A, Carmichael ST (1992) Anatomical organization of the primate amygdaloid complex. In: The amygdala: neurobiological aspects of emotion, memory, and mental dysfunction (Aggleton JP, ed), pp 1-66. New York: Wiley.

Arató M, Bánki CM, Bissette G, Nemeroff CB (1989) Elevated CSF CRF in suicide victims. Biol Psychiatry 25:355-359.

Arborelius L, Owens MJ, Plotsky PM, Nemeroff CB (1999) The role of corticotropin-releasing factor in depression and anxiety disorders. J Endocrinol 160:1-12.

Bánki CM, Bissette G, Arato M, O'Connor L, Nemeroff CB (1987) CSF corticotropin-releasing factor-like immunoreactivity in depression and schizophrenia. Am J Psychiatry 144:873-877.

Bao AM, Meynen G, Swaab DF (2008) The stress system in depression and neurodegeneration: focus on the human hypothalamus. Brain Res Rev 57:531-553.

Berman MG, Peltier S, Nee DE, Kross E, Deldin PJ, Jonides J (2011) Depression, rumination and the default network. Soc Cogn Affect Neurosci 6:548-555.

Bernstein DP, Fink L, Handelsman L, Foote J, Lovejoy M, Wenzel K, Sapareto E, Ruggiero J (1994) Initial reliability and validity of a new retrospective measure of child abuse and neglect. Am J Psychiatry 151:1132-1136.

Blomeyer D, Treutlein J, Esser G, Schmidt MH, Schumann G, Laucht M (2008) Interaction between CRHR1 gene and stressful life events predicts adolescent heavy alcohol use. Biol Psychiatry 63:146-151.

Boyce P, Parker G, Barnett B, Cooney M, Smith F (1991) Personality as a vulnerability factor to depression. Br J Psychiatry 159:106-114.

Bradley MM, Lang PJ (1999) Affective norms for English words (ANEW). Gainesville, FL: NIMH Center for the Study of Emotion and Attention.

Bradley RG, Binder EB, Epstein MP, Tang Y, Nair HP, Liu W, Gillespie CF, Berg T, Evces M, Newport DJ, Stowe ZN, Heim CM, Nemeroff CB, Schwartz A, Cubells JF, Ressler KJ (2008) Influence of child abuse on adult depression: moderation by the corticotropin-releasing hormone receptor gene. Arch Gen Psychiatry 65:190-200.

Brett M, Anton JL, Valabregue R, Poline JB (2002) Region of interest analysis using an SPM toolbox. Abstract presented at the 8th International Conference on Functional Mapping of the Human Brain, June 2-6, 2002, Sendai, Japan.

Canli T, Sivers H, Thomason ME, Whitfield-Gabrieli S, Gabrieli JD, Gotlib IH (2004) Brain activation to emotional words in depressed vs healthy subjects. Neuroreport 15:2585-2588.

Carver CS, White TL (1994) Behavioral inhibition, behavioral activation, and affective responses to impending reward and punishment: The BIS/BAS scales. J Pers Soc Psychol 67:319-333.

Cooney RE, Joormann J, Eugène F, Dennis EL, Gotlib IH (2010) Neural correlates of rumination in depression. Cogn Affect Behav Neurosci 10:470-478.

Costa PT Jr, McRae RR (1992) Revised NEO Personality Inventory (NEOPI-R) and NEO Five-Factor Inventory (NEO-FFI) professional manual. Odessa, FL: Psychological Assessment Resources.

Davidson RJ, Abercrombie H, Nitschke JB, Putnam K (1999) Regional brain function, emotion and disorders of emotion. Curr Opin Neurobiol 9:228-234.

Drevets WC (1999) Prefrontal cortical-amygdalar metabolism in major depression. Ann N Y Acad Sci 877:614-637.

Dunn AJ, Berridge CW (1990) Physiological and behavioral responses to corticotropin-releasing factor administration: is CRF a mediator of anxiety or stress responses? Brain Res Brain Res Rev 15:71-100.

Durrett C, Trull TJ, Silk K (2004) Retrospective measures of childhood abuse: concurrent validity and reliability in a nonclinical sample with borderline features. J Pers Disord 18:178-192.
Fredrikson M, Fischer H, Wik G (1997) Cerebral blood flow during anxiety provocation. J Clin Psychiatry. 58 [Suppl 16]:16-21.

Glover GH, Law CS (2001) Spiral-in/out BOLD fMRI for increased SNR and reduced susceptibility artifacts. Magn Reson Med 46:515-522.

Gotlib IH, Sivers H, Gabrieli JD, Whitfield-Gabrieli S, Goldin P, Minor KL, Canli T (2005) Subgenual anterior cingulate activation to valenced emotional stimuli in major depression. Neuroreport 16:1731-1734.

Grabe HJ, Schwahn C, Appel K, Mahler J, Schulz A, Spitzer C, Fenske K, Barnow S, Lucht M, Freyberger HJ, John U, Teumer A, Wallaschofski H, Nauck M, Völzke H (2010) Childhood maltreatment, the corticotropinreleasing hormone receptor gene and adult depression in the general population. Am J Med Genet B Neuropsychiatr Genet 153B:1483-1493.

Gray JA (1990) Brain systems that mediate both emotion and cognition. Cogn Emot 4:269-288.

Heim C, Bradley B, Mletzko TC, Deveau TC, Musselman DL, Nemeroff CB, Ressler KJ, Binder EB (2009) Effect of childhood trauma on adult depression and neuroendocrine function: sex-specific moderation by $\mathrm{CRH}$ receptor 1 gene. Front Behav Neurosci 3:41.

Heimer L, Zahm DS, Churchill L, Kalivas PW, Wohltmann C (1991) Specificity in the projection patterns of accumbal core and shell in the rat. Neuroscience 41:89-125.

Hodgkinson CA, Yuan Q, Xu K, Shen PH, Heinz E, Lobos EA, Binder EB, Cubells J, Ehlers CL, Gelernter J, Mann J, Riley B, Roy A, Tabakoff B, Todd RD, Zhou Z, Goldman D (2008) Addictions biology: haplotype-based analysis for 130 candidate genes on a single array. Alcohol Alcohol 43:505-515.

Holsboer F, Barden N (1996) Antidepressants and hypothalamic-pituitaryadrenocortical regulation. Endocr Rev 17:187-205.

Hsu DT, Price JL (2007) Midline and intralaminar thalamic connections with the orbital and medial prefrontal networks in macaque monkeys. J Comp Neurol 504:89-111.

Hsu DT, Price JL (2009) The paraventricular thalamic nucleus: subcortical connections and innervation by serotonin, orexin, and corticotropinreleasing hormone in macaque monkeys. J Comp Neurol 512:825-848.

Ivy AS, Rex CS, Chen Y, Dubé C, Maras PM, Grigoriadis DE, Gall CM, Lynch G, Baram TZ (2010) Hippocampal dysfunction and cognitive impairments provoked by chronic early-life stress involve excessive activation of CRH receptors. J Neurosci 30:13005-13015.

Kasch KL, Rottenberg J, Arnow BA, Gotlib IH (2002) Behavioral activation and inhibition systems and the severity and course of depression. J Abnorm Psychol 111:589-597.

Keedwell PA, Drapier D, Surguladze S, Giampietro V, Brammer M, Phillips M (2010) Subgenual cingulate and visual cortex responses to sad faces predict clinical outcome during antidepressant treatment for depression. J Affect Dis 120: 120-125.

Kendler KS, Neale MC, Kessler RC, Heath AC, Eaves LJ (1993) A longitudinal twin study of personality and major depression in women. Arch Gen Psychiatry 50:853-862.

Koenigsberg HW, Fan J, Ochsner KN, Liu X, Guise K, Pizzarello S, Dorantes C, Tecuta L, Guerreri S, Goodman M, New A, Flory J, Siever LJ (2010) Neural correlates of using distancing to regulate emotional responses to social situations. Neuropsychologia 48:1813-1822.

Kuchinke L, Jacobs AM, Grubich C, Võ ML, Conrad M, Herrmann M (2005) Incidental effects of emotional valence in single word processing: an fMRI study. Neuroimage 28:1022-1032.

Langenecker SA, Kennedy SE, Guidotti LM, Briceno EM, Own LS, Hooven T, Young EA, Akil H, Noll DC, Zubieta JK (2007) Frontal and limbic activation during inhibitory control predicts treatment response in major depressive disorder. Biol Psychiatry 62:1272-1280.

Leppänen JM (2006) Emotional information processing in mood disorders: a review of behavioral and neuroimaging findings. Curr Opin Psychiatry 19:34-39.

Licinio J, O'Kirwan F, Irizarry K, Merriman B, Thakur S, Jepson R, Lake S, Tantisira KG, Weiss ST, Wong ML (2004) Association of a corticotropin-releasing hormone receptor 1 haplotype and antidepressant treatment response in Mexican-Americans. Mol Psychiatry 9:1075-1082.

Liu Z, Zhu F, Wang G, Xiao Z, Wang H, Tang J, Wang X, Qiu D, Liu W, Cao Z, Li W (2006) Association of corticotropin-releasing hormone receptorl gene SNP and haplotype with major depression. Neurosci Lett 404:358-362.

Liu Z, Zhu F, Wang G, Xiao Z, Tang J, Liu W, Wang H, Liu H, Wang X, Wu 
Y, Cao Z, Li W (2007) Association study of corticotropin-releasing hormone receptor 1 gene polymorphisms and antidepressant response in major depressive disorders. Neurosci Lett 414:155-158.

Mayberg HS, Liotti M, Brannan SK, McGinnis S, Mahurin RK, Jerabek PA, Silva JA, Tekell JL, Martin CC, Lancaster JL, Fox PT (1999) Reciprocal limbic-cortical function and negative mood: converging PET findings in depression and normal sadness. Am J Psychiatry 156:675-682.

Mayberg HS, Brannan SK, Tekell JL, Silva JA, Mahurin RK, McGinnis S, Jerabek PA (2000) Regional metabolic effects of fluoxetine in major depression: serial changes and relationship to clinical response. Biol Psychiatry $48: 830-843$.

McRae K, Hughes B, Chopra S, Gabrieli JD, Gross JJ, Ochsner KN (2010) The neural bases of distraction and reappraisal. J Cogn Neurosci 22:248-262.

Merali Z, Du L, Hrdina P, Palkovits M, Faludi G, Poulter MO, Anisman H (2004) Dysregulation in the suicide brain: mRNA expression of corticotropin-releasing hormone receptors and $\mathrm{GABA}(\mathrm{A})$ receptor subunits in frontal cortical brain region. J Neurosci 24:1478-1485.

Millan MA, Jacobowitz DM, Hauger RL, Catt KJ, Aguilera G (1986) Distribution of corticotropin-releasing factor receptors in primate brain. Proc Natl Acad Sci U S A 83:1921-1925.

Nemeroff CB, Widerlöv E, Bissette G, Walléus H, Karlsson I, Eklund K, Kilts CD, Loosen PT, Vale W (1984) Elevated concentrations of CSF corticotropin-releasing factor-like immunoreactivity in depressed patients. Science 226:1342-1344.

Nemeroff CB, Owens MJ, Bissette G, Andorn AC, Stanley M (1988) Reduced corticotropin releasing factor binding sites in the frontal cortex of suicide victims. Arch Gen Psychiatry 45:577-579.

Owens MJ, Nemeroff CB (1991) Physiology and pharmacology of corticotropin-releasing factor. Pharmacol Rev 43:425-473.

Pizzagalli DA, Holmes AJ, Dillon DG, Goetz EL, Birk JL, Bogdan R, Dougherty DD, Iosifescu DV, Rauch SL, Fava M (2009) Reduced caudate and nucleus accumbens response to rewards in unmedicated subjects with major depressive disorder. Am J Psychiatry 166:702-710.

Polanczyk G, Caspi A, Williams B, Price TS, Danese A, Sugden K, Uher R, Poulton R, Moffitt TE (2009) Protective effect of CRHR1 gene variants on the development of adult depression following childhood maltreatment: replication and extension. Arch Gen Psychiatry 66:978-985.

Price CJ (2000) The anatomy of language: contributions from functional neuroimaging. J Anat 197:335-359.

Ressler KJ, Bradley B, Mercer KB, Deveau TC, Smith AK, Gillespie CF, Nemeroff CB, Cubells JF, Binder EB (2010) Polymorphisms in CRHR1 and the serotonin transporter loci: gene $\times$ gene $\times$ environment interactions on depressive symptoms. Am J Med Genet B Neuropsychiatr Genet 153B:812-824.
Sánchez MM, Young LJ, Plotsky PM, Insel TR (1999) Autoradiographic and in situ hybridization localization of corticotropin-releasing factor 1 and 2 receptors in nonhuman primate brain. J Comp Neurol 408:365-377.

Schmid B, Blomeyer D, Treutlein J, Zimmermann US, Buchmann AF, Schmidt MH, Esser G, Rietschel M, Banaschewski T, Schumann G, Laucht M (2010) Interacting effects of CRHR1 gene and stressful life events on drinking initiation and progression among 19-year-olds. Int J Neuropsychopharmacol 13:703-714.

Sheline YI, Barch DM, Donnelly JM, Ollinger JM, Snyder AZ, Mintun MA (2001) Increased amygdala response to masked emotional faces in depressed subjects resolves with antidepressant treatment: an fMRI study. Biol Psychiatry 50:651-658.

Siegle GJ, Steinhauer SR, Thase ME, Stenger VA, Carter CS (2002) Can't shake that feeling: fMRI assessment of sustained amygdala activity in response to emotional information in depressed individuals. Biol Psychiatry 51:693-707.

Tyrka AR, Price LH, Gelernter J, Schepker C, Anderson GM, Carpenter LL (2009) Interaction of childhood maltreatment with the corticotropinreleasing hormone receptor gene: effects on hypothalamic-pituitaryadrenal axis reactivity. Biol Psychiatry 66:681-685.

Tzourio-Mazoyer N, Landeau B, Papathanassiou D, Crivello F, Etard O, Delcroix N, Mazoyer B, Joliot M (2002) Automated anatomical labeling of activations in SPM using a macroscopic anatomical parcellation of the MNI MRI single-subject brain. Neuroimage 15:273-289.

Wang XD, Rammes G, Kraev I, Wolf M, Liebl C, Scharf SH, Rice CJ, Wurst W, Holsboer F, Deussing JM, Baram TZ, Stewart MG, Müller MB, Schmidt MV (2011) Forebrain CRF1 modulates early-life stress-programmed cognitive deficits. J Neurosci 31:13625-13634.

Wasserman D, Sokolowski M, Rozanov V, Wasserman J (2008) The CRHR1 gene: a marker for suicidality in depressed males exposed to low stress. Genes Brain Behav 7:14-19.

Wasserman D, Wasserman J, Rozanov V, Sokolowski M (2009) Depression in suicidal males: genetic risk variants in the CRHR1 gene. Genes Brain Behav 8:72-79.

Whalen PJ, Shin LM, Somerville LH, McLean AA, Kim H (2002) Functional neuroimaging studies of the amygdala in depression. Semin Clin Neuropsychiatry 7:234-242.

Widerlöv E, Bissette G, Nemeroff CB (1988) Monoamine metabolites, corticotropin releasing factor and somatostatin as CSF markers in depressed patients. J Affect Disord 14:99-107.

Zink CF, Pagnoni G, Martin-Skurski ME, Chappelow JC, Berns GS (2004) Human striatal responses to monetary reward depend on saliency. Neuron 42:509-517. 